\title{
Multiple paternity in Asclepias syriaca using a paired-fruit analysis
}

\author{
Julie J. Gold and Joel S. Shore
}

\begin{abstract}
We investigated the extent of multiple paternity within and between fruits of the common milkweed, Asclepias syriaca, at one site. Using isozyme polymorphisms at four loci and the maximum likelihood methods of Williams and Evarts (1989), we found no statistical evidence for multiple paternity within fruits. When pairs of fruits obtained from individual ramets were analyzed in a similar manner, extensive multiple paternity was observed, indicating that fruits on the same ramet are sired by different paternal parents. This extensive multiple paternity between fruits provides considerable opportunity for maternal choice via selective fruit abortion.
\end{abstract}

Key words: Asclepias, isozyme polymorphisms, multiple paternity, pollinia.

\begin{abstract}
Résumé : Les auteurs ont examiné l'étendue de la paternité multiple à l'intérieur et entre les fruits du laiteron, l'Asclepias syriaca, sur un site. En utilisant les polymorphismes isozymiques de quatre lieux et les méthodes de vraisemblance maximale de Williams et Evarts (1989), les auteurs n'ont perçu aucune évidence statistique supportant la paternité multiple à l'intérieur des fruits. Lorsque des paires de fruits obtenues de ramètes individuelles sont analysées de la même manière, on observe une paternité multiple générale, ce qui indique que les fruits portés sur une même ramète sont engendrés par différents parents paternels. Cette paternité multiple générale entre les fruits fournit une opportunité considérable pour le choix maternel, via un avortement sélectif des fruits.
\end{abstract}

Mots clés : Asclepias, polymorphismes isozymiques, paternité multiple, pollinies.

[Traduit par la rédaction]

\section{Introduction}

Milkweeds have provided excellent experimental systems for detailed investigations of mating patterns, estimates of gene flow via pollen, and tests of hypotheses concerning the role of male versus female reproductive success in determining the evolution of inflorescence size (e.g., Willson and Rathcke 1974; Wyatt 1976, 1980; Willson and Price 1977; Bookman 1984; Broyles and Wyatt 1990a, 1990b, 1991; Wyatt and Broyles 1990, 1994; Shore 1993). The pollination system of milkweeds, involving the simultaneous transfer of hundreds of pollen grains, may provide a system that allows increased precision in determining the identity of the paternal genotype, thus making milkweeds particularly amenable to paternity studies. This is because, at least for the one study carried out to date, pollen from a single paternal source appears to commonly fertilize all ovules within a fruit, more readily enabling a determination of the diploid paternal genotype (Broyles and Wyatt 1990a; Wyatt and Broyles 1994).

In this paper, we determine patterns of paternity in a population of the common milkweed, Asclepias syriaca L., by investigating the extent of within- and between-fruit multiple

Received December 29, 1994.

J.J. Gold ${ }^{1}$ and J.S. Shore. ${ }^{2}$ Department of Biology, York University, North York, ON M3J 1P3, Canada.

1 Present address: Department of Genetics and Molecular Biology, University of Guelph, Guelph, ON N1G 4S4, Canada.

2 Author to whom all correspondence should be addressed. paternity. We use isozyme polymorphisms to determine the genotype of seeds from two fruits for each of a number of plants and use this information to assess the extent of multiple paternity. The results provide further support for the common occurrence of single paternity within fruits but show extensive multiple paternity among fruits of single ramets. We discuss the ramifications of the observed patterns of paternity for the operation of sexual selection via maternal choice.

\section{Methods}

Asclepias syriaca is a native perennial found in fields, meadows, and roadsides across eastern and central North America. It reproduces sexually by windborne seed and asexually by horizontally spreading rhizomes. It has stout simple stems that may reach more than a metre in height, and broad, oval, opposite leaves. Axillary or terminal peduncles bear compact umbels with many flowers. Pollen of each anther sac is united into a mass known as a pollinium. A central, elastic, appendage, the corpusculum, joins two adjacent pollinia from different anthers (Bookman 1981; Newton 1984; Wyatt 1976). The paired pollinia (pollinarium) are dispersed by becoming attached to insect visitors by the corpusculum. Pollinia are delivered intact and, for successful pollination, must be lodged in the stigmatic chamber so that the convex edge of a pollinium contacts the stigmatic surface within the chamber (Wyatt 1976). Plants of $A$. syriaca are self-incompatible (Sparrow and Pearson 1948; Kephart 1981; Wyatt and Broyles 1994) and, at our site, are visited by a number of pollinating insects, particularly Apis mellifera and Bombus sp. Although numerous flowers are produced by plants; fewer than $2 \%$ of the flowers

Can. J. Bot. 73: 1212-1216 (1995). Printed in Canada / Imprimé au Canada 
eventually set fruit (Wyatt and Broyles 1990, 1994).

\section{Study site and sample collection}

The study site was a portion of an old field community of approximately 150 by $240 \mathrm{~m}$ situated on the York University campus (Toronto, Canada). In September 1988, we identified every fruit-bearing ramet $(N=131)$ in the study area and covered all developing pods with mesh bags to prevent seed loss upon fruit dehiscence. A leaf was removed from fruiting ramets and frozen at $-20^{\circ} \mathrm{C}$. All fruits $(N=422)$ were collected when ripe, and seeds were removed from each pod and stored in paper envelopes.

\section{Electrophoretic analysis}

From among all fruiting ramets collected, we sampled 33 ramets that possessed at least two pods, for electrophoretic analyses. For ramets with greater than two pods, we randomly chose two for analysis. Our sample, therefore, consisted of 33 pairs of pods sampled from 33 open-pollinated maternal plants. Thirty seeds were germinated per pod by procedures adapted from Baskin and Baskin (1977). After imbibition in Petri plates containing $30 \mathrm{~mL}$ of $0.01 \mu \mathrm{g} / \mathrm{mL}$ gibberellic acid, each of the seeds was etched along the longitudinal axis of the concave side to expose the hypocotyl root axis. These were returned to their Petri plate, kept at room temperature, and distilled $\mathrm{H}_{2} \mathrm{O}$ was added as needed, until seeds began to germinate. Germinating seeds (and frozen leaf tissue from maternal plants sampled in the field) were ground in $0.05 \mathrm{M}$ $\mathrm{Na}_{2} \mathrm{HPO}_{4}(\mathrm{pH}=7.0)$ buffer containing $1 \mathrm{mg} / \mathrm{mL}$ dithiothreitol and $20 \mathrm{mg}$ of polyvinylpolypyrrolidone. Extracts were frozen at $-20^{\circ} \mathrm{C}$ in $1.5-\mathrm{mL}$ microcentrifuge tubes until they could be assayed using horizontal starch gel electrophoresis.

Maternal and progeny tissues were initially screened for genetic variation in 18 enzymes. Four enzymes gave both good resolution and some degree of polymorphism. Starch gel electrophoresis was carried out following the methods cited in Shore and Barrett (1987) and Shore (1993). Ten seedlings from each of 33 pairs of pods as well as maternal tissue from each of the 33 ramets were assayed for their genotype at four isozyme loci. Phosphoglucomutase $(P g m-1)$, 6-phosphogluconate dehydrogenase $(P g d-2)$, and malate dehydrogenase $(M d h-l)$ were assayed using a histidine-citrate buffer system (Cardy et al. 1980), and glutamate dehydrogenase (Gdh-I) was assayed using a discontinuous buffer system (Poulik 1957).

\section{Multiple-paternity analyses}

We used the methods of Williams and Evarts (1989) to obtain maximum likelihood estimates of the extent of multiple paternity both within $\left(\phi_{\mathrm{w}}\right)$ and between $\left(\phi_{\mathrm{b}}\right)$ fruits of $A$. syriaca. The frequency of the most common allele $(p)$ at each locus is also estimated simultaneously. The method assumes that two kinds of matings occur, one involving single paternity and the other, multiple paternity. When multiple paternity occurs, it is assumed that only two paternal parents are involved and that each has an equal chance of siring progeny. Mating is assumed to be random. The procedure does not use data from loci containing multiple alleles. Prior to the analysis, it was necessary to convert data from loci with more than two alleles to a diallelic state. This was done by retaining the most common allele and pooling all others into a second composite allelic class. Because this procedure involves some loss of information, we also inspected single and paired pod progeny arrays for direct evidence of multiple paternity within and between pods.

To carry out the multiple-paternity analyses we first assigned maternal genotypes, at each of four isozyme loci, to each maternal parent directly (using the genotype determined from maternal leaf tissue), or deduced the maternal genotype by inspection of progeny arrays from both fruits assayed from the same maternal plant. In some instances, because of missing data on the maternal parent's genotype at one or more loci and incomplete information on the maternal genotype from the progeny arrays, we assigned the most likely maternal genotype using the progeny arrays, following Brown and Allard (1970) and Brown et al. (1986).

We analyzed the progeny-array data in two ways. First we determined whether there was evidence for multiple paternity within fruits $\left(\phi_{\mathrm{w}}\right)$ by analyzing the data from the total of 66 fruits (66 progeny arrays, approximately 10 progeny per array). We then pooled the progeny arrays for each pair of pods sampled from the same maternal plant (ramet) and reanalyzed the data to determine the extent of multiple paternity $\left(\phi_{\mathrm{b}}\right)$ between fruits (33 progeny arrays, approximately 20 progeny per array). For both analyses we estimated both $\phi$ and $p$ for each of the four polymorphic loci and provide a combined 4-locus estimate. We also analyzed the singlelocus data assuming the maternal genotypes were unknown. Multiple-paternity analyses were carried out using programs provided by C.J. Williams.

\section{Results}

We set out to determine the patterns of paternity in common milkweed and, in particular, the extent of within-pod versus between-pod multiple paternity. Because we assayed plants from a large population and only assayed a fraction of the flowering and fruiting plants, we used probabilistic methods to assess the degree of multiple paternity using the methods of Williams and Evarts (1989). The extent of multiple paternity, $\phi$, ranges from 0 (indicating single paternity) to 1 (indicating that multiple paternity has occurred for all progeny arrays). We used four polymorphic loci to analyze the extent of multiple paternity. $M d h-I$ and $P g d-2$ were polymorphic for two alleles, while $G d h-1$ and $P g m-1$ were polymorphic for three and four alleles, respectively. For the latter two loci it was necessary to pool the low-frequency alleles into a single allelic class (see Methods).

Our analysis of paternity within fruits revealed no evidence for multiple paternity (Table 1), as might be predicted for a species with a pollination system involving pollinia. Values of the probability of multiple paternity within fruits for individual loci ranged from 0.0 to 0.24 . The largest values occurred for $G d h-1$, which showed a low level of polymorphism and a large standard error. The multilocus estimate was $0.088 \pm 0.083$, thus providing no statistical evidence for a departure from single paternity within pods. An inspection of the progeny array data provided no directly observable instances of multiple paternity within fruits. We also analyzed the data assuming maternal genotypes were unknown and obtained comparably low levels of multiple paternity.

When progeny arrays were pooled to test for between-pod (within plant) multiple paternity, the results were markedly different (Table 1). Three of the four single-locus estimates 
Table 1. Estimates of the proportion of multiple paternity, $\phi$, and the frequency of the most common allele, $p$, occurring within and between pods.

\begin{tabular}{|c|c|c|}
\hline Locus & $\phi$ & $p$ \\
\hline \multicolumn{3}{|c|}{ Within pods } \\
\hline$G d h$ & $0.238(0.774)$ & $0.925(0.155)$ \\
\hline$M d h-1$ & $0.0 \quad(0.306)$ & $0.942(0.021)$ \\
\hline$P g d-2$ & $0.026(0.201)$ & $0.648(0.034)$ \\
\hline Pgm-1 & $0.175(0.149)$ & $0.517(0.034)$ \\
\hline 4-locus & $0.088(0.083)$ & - \\
\hline \multicolumn{3}{|c|}{ Between pods } \\
\hline$G d h-l$ & $(0.363)$ & $0.922(0.034)$ \\
\hline$M d h-1$ & $0.845(0.233)$ & $0.936(0.021)$ \\
\hline$P g d-2$ & $1.0 \quad(0.255)$ & $0.652(0.037)$ \\
\hline$P g m-1$ & $1.0 \quad(0.171)$ & $0.514(0.037)$ \\
\hline 4-locus & $1.062(0.091)$ & - \\
\hline
\end{tabular}

Note: Analyses are provided for each locus as well as for a combined 4-locus estimate. Standard errors are given in parentheses.

were 1.0 , indicating that multiple paternity commonly occurs between pods on plants. The multilocus estimate was $1.06 \pm$ 0.09 . The between-pod data are therefore consistent with the occurrence of extensive or complete multiple paternity between pods, indicating that different pods on the same plant are sired by different paternal parents. Direct inspection of the pairs of progeny arrays provided seven unambiguous cases of directly observable multiple paternity (i.e., these were instances where more alleles occurred among the progeny than could be accounted for by a single paternal parent). There were two pairs of progeny arrays for which the same genotypes occurred among the progeny of both pairs of arrays for all four loci. These two sets of arrays provided no direct evidence for multiple paternity.

Milkweed plants at our site showed typically low levels of fruit set per ramet. Most ramets at the site did not produce any fruit. The distribution of numbers of fruit per fruiting ramet is provided in Fig. 1. The distribution is positively skewed and shows that most fruiting ramets produce two fruits (range $1-19$ ), while one unusual individual produced 19 fruits. When we couple this information with our paternity study, then $79 \%$ of ramets produce at least two fruits (each containing seeds that are full-sibs), with the progeny between fruits being related as half-sibs ( $48 \%$ of ramets produce three or more such arrays of half-sib progeny). Multiple paternity between fruits, therefore, enhances the extent of genetic variation in the offspring in the face of greater genetic uniformity of progeny within fruit.

\section{Discussion}

We used the maximum likelihood methods of Williams and Evarts (1989) to analyze the extent of multiple paternity. The structure of our sampling scheme closely matches the assumptions inherent in their model requiring two paternal parents each fertilizing an equal proportion of ovules. This is because there is single paternity within pods and because we sampled equal numbers of progeny from each of two pods per plant.
Fig. 1. Frequency distribution for fruiting plants, of the number of plants having various numbers of pods per plant.

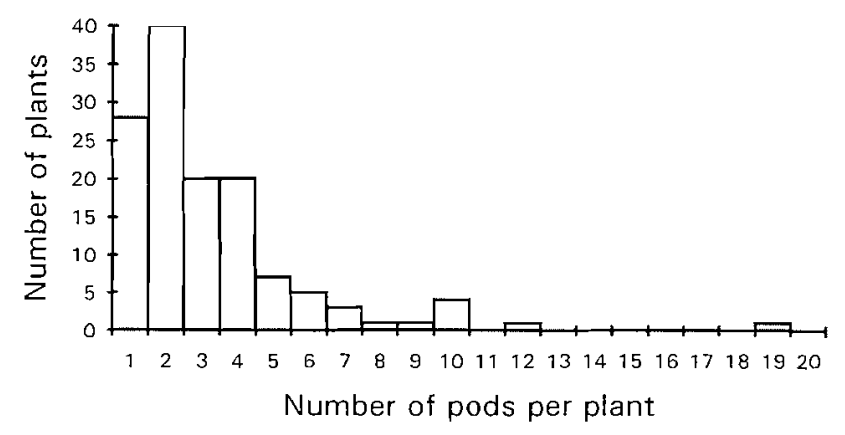

Our results provide the first paternity analyses for $A$. syriaca and are comparable to those observed by Broyles and Wyatt (1990a) for Asclepias exaltata. Using the methods of Williams and Evarts (1989) they also found no statistical evidence for multiple paternity within fruits. At the between-fruit level, their values of multiple paternity ranged from 0.82 to 1.0 . This was the case even when the fruits had developed from ovaries within a single flower (Broyles and Wyatt 1990a). Taken together, these studies suggest that the pollination system of Asclepias leads to single paternity within pods but multiple paternity between pods.

Paternity studies have now been carried out for species that disperse pollen grains individually (Ellstrand 1984; Schoen 1985; Brown et al. 1986; Ellstrand and Marshall 1986; Meagher 1986; Ritland 1989; Dudash and Ritland 1991), in polyads of 16 pollen grains (Muona et al. 1991), or in pollinia (Broyles and Wyatt 1990a). Ellstrand (1984) found extensive multiple paternity within fruits of outcrossing Raphanus sativus with a minimum of $85 \%$ fruits containing seeds resulting from two or more paternal parents. Brown et al. (1986) found evidence for multiple paternity within $65 \%$ of the fruits of the more highly selfing Glycine argyrea, including fruits containing seeds sired by self and outcross pollen. Ritland (1989) and Dudash and Ritland (1991) estimated the correlation of paternity to infer the extent of multiple paternity within fruits of Mimulus guttatus. Their results suggest that 60-80\% of fruits contain seeds resulting from multiple paternity. Schoen (1985) found no evidence for a correlation of mating events within cones of wind-pollinated Picea glauca, thus providing evidence for high levels of multiple paternity.

The proximate causes of multiple paternity within fruits of insect-pollinated species that disperse grains individually have been investigated. Pollen primacy (the fertilization advantage of the first pollen to arrive on a stigma) coupled with the degree of pollen carryover appear to be the most important factors determining the extent of multiple paternity within a fruit. Later deposition of pollen can increase the degree of multiple paternity but appears to play a minor role (Marshall and Ellstrand 1985; Epperson and Clegg 1987; Dudash and Ritland 1991). The importance of subsequent pollinations should, however, increase if the ratio of the number of pollen grains deposited per pollinator visit is less than the number required to achieve full seed set.

In contrast with species dispersing grains individually, Muona et al. (1991) found low rates of multiple paternity within fruits (range $0-37 \%$ ) of Acacia melanoxylon. This species disperses pollen in polyads composed of 16 pollen 
grains which is sufficient to fertilize all ovules in an ovary. The pollinia-bearing species $A$. exaltata (Broyles and Wyatt $1990 a$ ) and $A$. syriaca (studied here) show virtually complete single paternity within fruits.

A number of aspects of the reproductive system of milkweeds might enforce single paternity within fruits. For example, in A. syriaca, Wyatt and Broyles (1992) have shown that the number of pollen grains per pollinium exceeds the number of ovules per ovary by approximately $40 \%$. Thus there are ample pollen grains in a single pollinium to fertilize all ovules and the first pollen grains to arrive are likely to have a great fertilization advantage over those that arrive later. The presence of a self-incompatibility system will prevent the occurrence of fruits containing both selfed and outcrossed seeds (Broyles and Wyatt 1993), despite high levels of insertion of self pollinia (Pleasants 1991; Shore 1993). Sage et al. (1990) have shown in anatomical studies of Asclepias amplexicaulis that there appears to be some opportunity for multiple paternity to occur within fruits due to the partial fusion of styles of the paired ovaries found within flowers. This feature could provide a route for pollen tubes to cross from one style to the other and hence might result in multiple paternity if pollinia are inserted into opposite stigmatic chambers of a single flower. Sage et al. (1990), however, did not observe any instances of pollen tubes crossing from one style to the other in A. amplexicaulis, and this phenomenon appears to be infrequent in $A$. syriaca (Sparrow and Pearson 1948; Morse 1993).

Our observation of single paternity within fruits is in striking contrast to the extensive multiple paternity between fruits. This pattern of multiple paternity should have a number of consequences, including (i) limiting the opportunities for pollen competition; (ii) restricting the scope of sib competition within fruits; and (iii) limiting maternal choice to selective abortion among fruits, in contrast to species dispersing pollen grains individually, where there should be opportunities for selective abortion of ovules within fruits as well as between fruits. If the extent of multiple paternity for mature fruits that we have documented is a reflection of the extent of multiple paternity that occurs at the time of first initiation of fruiting (i.e., at the time of fertilization), then there would appear to be considerable opportunity for maternal choice among mates to occur through selective fruit abortion. Wyatt (1980), Bookman $(1983,1984)$, and Broyles and Wyatt (1990b) have provided evidence for selective abortion - maturation of fruits in Asclepias.

\section{Acknowledgements}

We thank Christopher Williams for kindly providing computer programs to carry out the paternity analyses, Steven Broyles for comments on the manuscript, Oron Anter and Cremilda Dias for technical assistance, and the Department of Biological Sciences at Florida State University for providing access to computing facilities. This study was funded by a Natural Sciences and Engineering Research Council of Canada grant to J.S.S.

\section{References}

Baskin, J.M., and Baskin, C.C. 1977. Germination of common milkweed (Asclepias syriaca L.) seeds. Bull. Torrey Bot. Club, 104: $167-170$.
Bookman, S.S. 1981. The floral morphology of Asclepias speciosa (Asclepiadaceae) in relation to pollination and a clarification in terminology for the genus. Am. J. Bot. 68: 675-679.

Bookman, S.S. 1983. Costs and benefits of flower abscission and fruit abortion in Asclepias speciosa. Ecology, 64: 264-273.

Bookman, S.S. 1984. Evidence for selective fruit production in Asclepias. Evolution, 38: 72-86.

Brown, A.H.D., and Allard, R.W. 1970. Estimation of the mating system in open-pollinated maize populations using isozyme polymorphisms. Genetics, 33: 133-145.

Brown, A.H.D., Grant, J.E., and Pullen, R. 1986. Outcrossing and paternity in Glycine argyrea by paired fruit analysis. Biol. J. Linn. Soc. 29: 283-294.

Broyles, S.B., and Wyatt, R. 1990a. Paternity analysis in a natural population of Asclepias exaltata: multiple paternity, functional gender, and the "pollen donation hypothesis." Evolution, 44: $1454-1468$.

Broyles, S.B., and Wyatt, R. 1990b. Plant parenthood in milkweeds: a direct test of the pollen donation hypothesis. Plant Species Biol, 5: 131-142.

Broyles, S.B., and Wyatt, R. 1991. Effective pollen dispersal in a natural population of Asclepias exaltata: the influence of pollinator behavior, genetic similarity, and mating success. Am. Nat. 138: $1239-1249$.

Broyles, S.B., and Wyatt, R. 1993. The consequences of selfpollination in Asclepias exaltata, a self-incompatible milkweed. Am. J. Bot. 80: 41-44.

Cardy, B.J., Stuber, C.W., and Goodman, M.M. 1980. Techniques for starch gel electrophoresis of enzymes from maize (Zea mays L.). Institute of Statistics mimeo series No. 1317. North Carolina State University, Raleigh, N.C.

Dudash, M.R., and Ritland, K. 1991. Multiple paternity and self-fertilization in relation to floral age in Mimulus guttatus (Scrophulariaceae). Am. J. Bot. 78: 1746-1753.

Ellstrand, N.C. 1984. Multiple paternity within the fruits of the wild radish, Raphanus sativus. Am. Nat. 123: 819-828.

Ellstrand, N.C., and Marshall, D.L. 1986. Patterns of multiple paternity in populations of Raphanus sativus. Evolution, 40: $837-842$.

Epperson, B.K., and Clegg, M.T. 1987. First-pollination primacy and pollen selection in the morning glory, Ipomoea purpurea. Heredity, 58: 5-14.

Kephart, S.R. 1981. Breeding systems in Asclepias incarnata L., $A$. syriaca L., and $A$. verticillata L. Am. J. Bot. 68: 226-232.

Marshall, D.L., and Ellstrand, N.C. 1985. Proximal causes of multiple paternity in wild radish, Raphanus sativus. Am. Nat. 126: $596-605$.

Meagher, T.R. 1986. Analysis of paternity within a natural population of Chamaelirium luteum. 1. Identification of most-likely male parents. Am. Nat. 128: 199-215.

Morse, D.H. 1993. The twinning of follicles by common milkweed Asclepias syriaca. Am. Midl. Nat. 130: 56-61.

Muona, O., Moran, G.F., and Bell, J.C. 1991. Hierarchical patterns of correlated mating in Acacia melanoxylon. Genetics, 127: $619-626$.

Newton, L.E. 1984. Terminology of structures associated with pollinia of the Asclepiadaceae. Taxon, 33: 612-619.

Pleasants, J.M. 1991. Evidence for short-distance dispersal of pollinia in Ascelpias syriaca L. Funct. Ecol. 5: 75-82.

Poulik, M.D. 1957. Starch gel electrophoresis in a discontinuous system of buffers. Nature (London), 180: 1477-1479.

Ritland, K. 1989. Correlated matings in the partial selfer Mimulus guttatus. Evolution, 43: 848-859.

Sage, T.L., Broyles, S.B., and Wyatt, R. 1990. The relationship between the five stigmatic chambers and two ovaries of milkweed flowers: a three dimensional assessment. Isr. J. Bot. 39: $187-196$. 
Schoen, D.J. 1985. Correlation between classes of mating events in two experimental plant populations. Heredity, 55: $381-385$.

Shore, J.S. 1993. Pollination genetics of the common milkweed, Asclepias syriaca. Heredity, 70: 101-108.

Shore, J., and Barrett, S.C.H. 1987. Inheritance of floral and isozyme polymorphisms in Turnera ulmifolia L. J. Hered. 78: 44-48.

Sparrow, F.K., and Pearson, N.L. 1948. Pollen compatibility in Asclepias syriaca. J. Agric. Res. (Washington, D.C.), 77: $187-199$.

Williams, C.J., and Evarts, S. 1989. The estimation of concurrent multiple paternity probabilities in natural populations. Theor. Popul. Biol, 35: $90-112$.

Willson, M.F., and Price, P.W. 1977. The evolution of inflorescence size in Asclepias (Asclepiadaceae). Evolution, 31: 495-511.
Willson, M.F., and Rathcke, B.J. 1974. Adaptive design of the floral display in Asclepias syriaca L. Am. Midl. Nat. 92: 47-57.

Wyatt, R. 1976. Pollination and fruit-set in Asclepias: a reappraisal. Am. J. Bot. 63: 845-851.

Wyatt, R. 1980. The reproductive biology of Asclepias tuberosa: I. Flower number, arrangement, and fruit-set. New Phytol. 85: $119-131$.

Wyatt, R., and Broyles, S.B. 1990. Reproductive biology of milkweeds (Asclepias): recent advances. In Biological approaches and evolutionary trends in plants. Edited by S. Kawano. Academic Press, Toronto. pp. 255-272.

Wyatt, R., and Broyles, S.B. 1992. Hybridization in North American Asclepias. III. Isozyme evidence. Syst. Bot. 17: 640-648.

Wyatt, R., and Broyles, S.B. 1994. Ecology and evolution of reproduction in milkweeds. Annu. Rev. Ecol. Syst. 25: 423-441. 